\title{
DESFLORESTAMENTO NA AMAZÔNIA \\ BRASILEIRA: ação coletiva, governança e governabilidade em área de fronteira
}

\section{Luciana de Oliveira Rosa Machado*}

\begin{abstract}
Resumo: Este trabalho tem como objetivo analisar o papel das políticas de ocupação e o uso dos recursos naturais da Amazônia e identificar em que medida essas políticas podem afetar o comportamento de determinados grupos em relação ao desflorestamento da região. Para tanto, apresenta os conceitos de capital social, ação coletiva, governança e governabilidade utilizados para tentar explicar o comportamento de alguns atores presentes na área de influência da rodovia BR-163 (Cuiabá-Santarém). Os resultados alcançados indicam que as políticas de controle do desflorestamento somente conseguirão influenciar o comportamento dos atores da região se houver uma ação mais efetiva do Estado, por meio da utilização de mecanismos de regulamentação. Essa ação deve levar em conta as relações de poder local e o reflexo delas sobre as taxas de desflorestamento. Finalmente, fica claro que o estabelecimento de instrumentos e incentivos econômicos capazes de interferir em comportamentos eminentemente individuais também deve ser parte de uma política de desenvolvimento regional.
\end{abstract}

Palavras-chave: Amazônia; desmatamento; participação social; regulamentação; instrumentos econômicos.

\section{Introdução}

O desflorestamento na Amazônia tem sido foco de preocupações de vários pesquisadores e especialistas em mudanças

\footnotetext{
* Bacharel em Direito e Engenharia Florestal e mestre em Desenvolvimento Sustentável pelo Centro de Desenvolvimento Sustentável da Universidade de Brasília (CDS/UnB). doutoranda em Desenvolvimento Sustentável, área de concentração Política e Gestão Ambiental, no CDS/UnB. E-mail: luciana.machado@mma.gov.br
}

Artigo recebido em 27 jan. 2009 e aprovado em 20 fev. 2009. 
climáticas. A região é considerada a maior fonte brasileira de emissão de gás carbônico para a atmosfera, contribuindo para o agravamento do efeito estufa. Estudos recentes apontam que a dinâmica do desflorestamento na Amazônia envolve diferentes agentes e fatores causadores, conforme a área de abrangência e o momento de sua realização (Machado, 2002, Margulis, 2002, Rodrigues, 2004). Isso revela que o fenômeno é bastante complexo e não deve ser atribuído a um único agente ou fator. Na verdade, ele é a soma de um conjunto de forças que se combinam entre si e interagem sinergicamente.

Por outro lado, parece haver certo consenso sobre o fato de que as políticas públicas desempenham um papel relevante nesse contexto. Nas décadas de 1970 e 1980, as taxas de desmatamento observadas eram atribuídas a políticas de incentivos fiscais e de crédito rural, a programas de colonização e a investimentos em infraestrutura que atraíram milhares de migrantes para a região. Mais recentemente, observa-se uma redução na maioria dessas variáveis. Entretanto, as taxas de desmatamento permanecem elevadas, o que indica que existem forças subjacentes ${ }^{1}$ que operam e determinam o futuro da cobertura florestal amazônica.

Embora a identificação dessas forças seja primordial para o entendimento do fenômeno, não é pretensão deste artigo analisar as causas do desflorestamento na região, mesmo porque esse tema foi bastante discutido em trabalhos anteriores (Machado, 2002; Margulis, 2002, Rodrigues, 2004, Fearnside, 2005a, 2006a, 2006b). O objetivo é discutir o papel do Estado e a importância das políticas públicas para reverter esse estado de coisas. ${ }^{2}$

Partindo do pressuposto de que, no contexto atual, a dinâmica e os problemas inerentes à Amazônia resultam mais da ausência do que da intervenção estatal (Cleary, 1993), tem-se que o sucesso das políticas de controle do desflorestamento está condicionado a uma ação mais efetiva do Estado na região, por meio de mecanismos e 
instrumentos de regulação. Depende também do envolvimento - e da responsabilização - da sociedade afetada nos processos decisórios e na implementação dessas políticas.

Se o Estado teve papel relevante no passado, hoje ele é percebido pela falta de ações práticas e políticas. Essa "ausência" abre espaços para a emergência de formas espontâneas de organização de grupos sociais e para a sua inserção - direta ou indireta - nos processos de tomada de decisão. Ainda que seja uma tendência global, esse processo tem um lado perverso, que é a apropriação do bem comum por setores da sociedade que, por sua conta e risco, organizam as suas atividades de acordo interesses próprios, deixando de lado o interesse coletivo. Para reverter essa situação, é preciso ampliar a ação reguladora do Estado, limitada no final do século XX pelo avanço do neoliberalismo. A governança moderna exige que o Estado, ainda que indiretamente, atue como a "mão invisível", buscando mecanismos de regulação, de gestão de contratos sociais e de promoção de instrumentos e políticas indutoras de estratégias planejadas (Bursztyn, 2001, p. 69).

Nessa perspectiva, o presente artigo discute o papel das políticas públicas (reguladoras e financeiras) e a medida em que essas políticas podem alterar o comportamento de determinados grupos envolvidos no desflorestamento da Amazônia. A análise foi feita com base nos conceitos de capital social e do dilema da ação coletiva, tendo como pano de fundo a pavimentação da rodovia BR - 163 que liga Cuiabá, no estado de Mato Grosso, a Santarém, no Pará.

Além desta introdução, o texto foi estruturado em seis partes. As duas primeiras trazem um breve histórico das políticas desenhadas em períodos anteriores para a região amazônica, notadamente para a área de influência da BR-163, e os seus impactos sobre o desflorestamento da Amazônia. A seção seguinte apresenta 
conceitos, como o de capital social e de ação coletiva, utilizados para tentar explicar o comportamento de alguns atores. Nas duas seções seguintes, discute-se a mobilização da sociedade civil e o papel do Estado no controle do desflorestamento na área de influência BR-163, combinando conceitos de governança e governabilidade. Finalmente, vêm as considerações finais, que atestam que o papel regulador do Estado, assim como o estabelecimento de incentivos econômicos, são essenciais para reverter o quadro de degradação em que se encontra a região. Da mesma maneira, o envolvimento e a responsabilização da sociedade também são elementos-chave para essa reversão.

\section{Políticas públicas de ocupação da Amazônia: breve contexto}

A ocupação da Região Amazônica deu-se em diversas fases, como resposta a mudanças no processo de desenvolvimento econômico em diferentes níveis, que vão desde o local e regional, até o nacional e o internacional. À exceção do vigoroso "ciclo da borracha”, registrado no final do século XIX e início do século XX, o desenvolvimento da região sempre esteve baseado em atividades de subsistência praticadas por populações tradicionais e indígenas. Essas atividades foram desenvolvidas durante séculos, com base numa estreita relação que essas comunidades mantinham com o meio ambiente, uma vez que dele dependiam para a sua sobrevivência.

A Segunda Guerra Mundial provocou a revalorização estratégica da borracha nativa da Amazônia, uma vez que as plantações asiáticas de seringueiras que a tinham deslocado do mercado mundial caíram sob o domínio japonês. Isso significou o bloqueio das exportações da borracha para os inimigos do Japão. Com isso, a ocupação da região amazônica entrou numa nova fase, estimulada por um processo de especialização da produção baseado na extração de 
produtos florestais. Novamente, milhares de nordestinos, fugidos da pobreza e da seca, foram estimulados pelo governo federal a migrar para a Amazônia para extrair o látex e buscar melhores condições de vida. Depois da guerra, no entanto, esse surto de ocupação se esvaziou. Pouco depois, no entanto, foi criado um novo estatuto jurídico para a região, que foi reconfigurada como "Amazônia Legal"3 (Lei no 1.806, de 1953). Essa medida complementou a promulgação de uma emenda constitucional que destinava $3 \%$ da renda tributárias da União, dos Estados e dos municípios amazônicos para serem gastos exclusivamente no desenvolvimento da região, dentro de um esquema mais amplo de sua valorização econômica e social (Miranda Neto, 1991). Foi também nesse momento que o governo criou mecanismos institucionais, como a Superintendência do Plano de Valorização da Amazônia (SPVEA) e o Banco de Crédito da Amazônia (antigo Banco da Borracha), para viabilizar e subsidiar a ocupação de terras à frente da expansão pioneira (Becker, 1998, Pasquis et al., 2001).

Após essas transformações, foi desencadeado pelo Governo Militar um processo de ocupação que era fundamentado na doutrina da segurança nacional. Dessa forma, o Estado passou a intervir na região no sentido de maximizar a sua produção econômica, lançando diferentes programas de desenvolvimento regional. Dentre eles, destacam-se os chamados programas de colonização e reforma agrária, que começaram a ser implantados no período militar. Foram elaborados também programas especiais de desenvolvimento regional, que tinham como premissa básica a incorporação da Região Amazônica, tida como detentora de grandes "espaços vazios", ao território nacional.

Com o golpe de 1964, a "Marcha para o Oeste" viabilizou a implantação de projetos agropecuários, de colonização e de expansão do agronegócio em regiões de fronteira. Essas medidas reforçaram o interesse das empresas privadas, principalmente 
as de grande porte, nacionais ou estrangeiras, que passaram a predominar, de modo ostensivo, na política de terras executada pelo governo federal (Sayago; Machado, 2004, p. 225). A propriedade da terra assumiu, nesse contexto, a forma hegemônica de grandes grupos privados que transformaram importantes capitalistas em latifundiários (Bartholo et al., 2005, p. 6). Esse processo foi possível, em grande medida, por causa institucionalização de programas especiais de desenvolvimento, implementados por meio da criação da Superintendência de Desenvolvimento da Amazônia (Sudam) e da Superintendência da Zona Franca de Manaus (Suframa).

Além da migração induzida, o Estado interveio na ocupação da Amazônia incentivando também a implantação de projetos de colonização privada. Para viabilizar esses projetos particulares de colonização, caberia ao Estado estimular, por meio de assistência técnica e financeira, a implantação de infra-estrutura e eletrificação rural. Assim, com a concessão de créditos subsidiados e incentivos fiscais, o governo federal promoveu a penetração de novos atores na região. Foi o caso das terras localizadas na área de influência da BR-163, onde predominaram a expansão de empreendimentos agropecuários, as articulações entre colonizadoras e colonos e a expansão da atividade madeireira.

Pode-se dizer, portanto, que o modelo de ocupação da Amazônia, ao longo das décadas de 1970 e 1980, esteve voltado essencialmente para as grandes empresas e fazendas, caracterizando uma forte atuação estatal com vista à substituição de importações e ao aumento de exportações por meio do aumento da produção nacional (Kitamura, 1994). Os programas desenvolvimentistas dessa época estavam voltados para a capitalização e modernização da agricultura, que passava por um processo de transformação tecnológica - também conhecido como "revolução verde".

Embora a economia amazônica tenha experimentado taxas de crescimento relativamente altas $-13,85 \%$ ao ano entre os anos 1970 
e 1990, levando a um significativo crescimento do PIB, os resultados dessas políticas ficaram bem aquém do desejado. De acordo com um estudo que relaciona física e temporalmente a entrada de grandes projetos agropecuários subsidiados e os movimentos dos preços da terra na Amazônia, as regiões que apresentaram as maiores elevações dos preços foram aquelas onde houve a entrada de grandes grupos econômicos, ocorrendo nesses mesmos locais, concomitantemente, elevados índices de destruição da floresta e os maiores conflitos pela terra (Reydon; Herbers, 1989).

Conclui-se, desse contexto, que o modelo desenvolvimentista predominante na história recente de ocupação da Amazônia - seja por questões de segurança nacional, seja por interesses políticos e econômicos diversos -, embora tenha trazido alguns ganhos em termos de economia regional, levou a região a um cenário de devastação ambiental. Entre 1976 e 1991, 14,07\% do território amazônico já haviam sido impactados, correspondendo ao total da área da Amazônia convertida em pastagens, áreas agrícolas, exploração madeireira e mineral, garimpo, extrativismo e áreas urbanas (Ferreira; Salati; Santos, [s. d.]). Mais recentemente, a chegada do agronegócio intensificou esse quadro, elevando ainda mais as taxas de desmatamento. O resultado acumulado disso atingiu, em 2007, mais de 700 mil km² de áreas desmatadas, ou 18\% do território amazônico (Prodes/Inpe, 2007).

A emergência desse cenário despertou a atenção da sociedade nacional e internacional e deu início a um processo de mobilização interna e externa, cujo objetivo era a elaboração de alternativas ao padrão de desenvolvimento, que deveria ser condicionado ambientalmente. Assim, em vez de incentivar o crescimento econômico puro e simples, as políticas públicas deveriam ser pautadas pela idéia de desenvolvimento sustentável, cuja premissa baseia-se na redução dos desperdícios, no aumento da eficácia no uso dos recursos naturais e em princípios de equidade social e oportunidades para as gerações atuais e futuras (Sachs, 2000). 


\section{Reflexos da ocupação territorial sobre as taxas de desflorestamento}

As conseqüências desse conjunto de propostas podem ser avaliadas com base em diferentes fatores, entre eles:

- a consolidação do "arco do desflorestamento", também conhecido como "arco de povoamento adensado" (Becker, 2004), que vai desde o sul do Pará, passando pelo norte de Mato Grosso, por Rondônia e sudoeste do Amazonas até chegar ao Acre;

- consolidação do "cinturão da soja", que acompanha este arco, com perspectivas de ocupar não apenas as áreas de cerrado, mas também as áreas de floresta de transição e áreas já desmatadas de Floresta Amazônica;

- poluição do ar em cidades como Manaus, Porto Velho, Rio Branco, Cuiabá, Sinop e Paragominas;

- aumento da taxa de antropização da floresta, por meio da exploração florestal e de projetos de reforma agrária;

- comprometimento do potencial hídrico e da biodiversidade amazônica decorrente do elevado grau de privatização do bem comum, como a privatização das florestas nacionais; e,

- aumento da taxa de desmatamento e incremento das queimadas, com consequente aumento do efeito estufa decorrente, elevando a participação do Brasil na emissão global de $\mathrm{CO}_{2}$ na atmosfera.

Este quadro se deve, em grande parte, ao fato de que os sistemas produtivos até agora implantados na região não conseguiram criar uma "socioeconomia" estável, por não terem levado em consideração as características do ambiente natural amazônico. Isso tem levado a região a um processo de degradação ambiental, que se traduz, entre outros, nos elevados índices de desflorestamento observados nos últimos anos. 
Em termos ambientais, o início da década de 1990 foi marcado por um clima tenso, em que denúncias e desconfianças a respeito de ações governamentais criavam condições para ampliar a mobilização em torno da Conferência do Rio (1992). Na perspectiva internacional, a Região Amazônica representa, hoje, uma reserva de recursos genéticos, especialmente para novas modalidades de transformação industrial. Por outro lado, a região contribui para a "amenização" dos problemas ambientais globais, entre eles, as mudanças climáticas, o seqüestro de carbono e a regulação das emissões de outros gases que permanecem na atmosfera e dão origem ao efeito estufa.

Outro reflexo importante relaciona-se a alterações introduzidas nos programas internacionais. Mesmo os programas destinados a atividades historicamente degradadoras passam a ser objeto de avaliação ambiental e se vêem obrigados a destinar uma parcela de seus recursos a um componente de conservação ou controle, fiscalização e monitoramento ambiental. A expressão "sustentável" passou a ser obrigatória, figurando em todos os projetos financiados com recursos externos. Todavia, conforme será discutido ao longo das seções subsequentes, mesmo com esses esforços, as políticas públicas - incluídas as ambientais, agrárias, agrícolas, energéticas, de transportes, de implantação de infra-estrutura etc. - continuam sendo elaboradas de forma independente e desarticulada. Além disso, elas não levam em conta o contexto em que se inserem, qual seja, a Amazônia Legal e toda a sua diversidade, nem a existência de grupos de interesse bem constituídos, que operam de acordo com lógicas próprias, buscando satisfazer apenas interesses setoriais ou individuais.

\section{O capital social e o dilema da ação coletiva}

A compreensão sobre o desenvolvimento de certas regiões brasileiras e a retração de outras é relativamente recente. Estudos 
elaborados nesta perspectiva não chegam a um consenso, mas convergem em um ponto importante: regiões dinâmicas são caracterizadas pela existência de uma rede de relações entre serviços e organizações públicas, iniciativas empresariais urbanas e rurais, agrícolas e não-agrícolas (Abramovay, 2000).

Nesse contexto, o conceito de capital social, definido como um "conjunto de recursos reais ou potenciais que se vinculam à posse de uma rede duradoura de relações mais ou menos institucionalizadas de conhecimento e reconhecimento mútuo" (Bourdieu, 1986), desponta como uma inovação bastante promissora da teoria social contemporânea. Por envolver a valorização das comunidades locais e de organizações não-governamentais, o conceito de capital social muda o foco do Estado para a sociedade civil, como entidade coprodutora do desenvolvimento (Rankin, 2001, Bebbington, 2008).

Ao colocar a sociedade em pé de igualdade com o Estado no que toca à promoção do desenvolvimento, acredita-se que o capital social possa ser utilizado também em contextos que envolvem questões ambientais. Isso porque o estabelecimento de "redes sociais" baseadas em características de organização social, como confiança, normas e sistemas, contribui para aumentar a eficiência da sociedade, facilitando ações coordenadas para a finalidade de obter bens públicos. Sendo o meio ambiente um bem público de uso comum da população, e considerando a co-responsabilidade da sociedade na promoção do desenvolvimento, o estabelecimento de ações coordenadas - Estado e sociedade - pode representar um ganho real na busca pelo desenvolvimento sustentável. Para tanto, é preciso que se leve em conta a realidade local e as relações de poder que ali se processam, elementos que nem sempre são considerados em estudos que visam promover capital social em determinadas comunidades.

Embora haja divergências com relação à aplicação do conceito (Coleman, 1990, Fine, 1999, 2001, Harriss, 2001, Cleaver, 2005, 
Putnam, 2005, Bebbington, 2007), o fato é que a confiança mútua e a interação continuada entre os indivíduos ajudam a enfrentar o dilema da ação coletiva (Axelrod, 1981). Dessa forma, se o capital social for analisado como variável dependente do processo de desenvolvimento, incorporando em sua aplicação o contexto local, os grupos de interesse constituídos e as diferentes relações de poder, ele pode ser ferramenta importante no enfrentamento de problemas ambientais.

À medida que o capital social surge como um conceito importante para entender o funcionamento das relações humanas e dos arranjos sociais estabelecidos em torno de um objetivo comum, ele pode ser utilizado para caracterizar as maneiras pelas quais os membros de uma comunidade interagem, permitindo entender os seus comportamentos em face de uma dada questão - neste caso, o desflorestamento da Amazônia. Ao mesmo tempo, o conceito serve como alternativa para enfrentar o dilema da ação coletiva nas relações sociais.

A teoria da ação coletiva parte do pressuposto de que os indivíduos são atores movidos por intenções, que perseguem objetivos específicos. Dessa forma, eles não ingressarão em grupos que lutam por um bem público a menos que haja coação, ou que eles percebam a ameaça de serem excluídos de alguma maneira do usufruto do bem, ou que eles sejam estimulados mediante algum benefício colateral ou bem privado (Olson, 1999).

Com relação ao desflorestamento, a ausência de um elemento de coação - o Estado, com seu poder extroverso e coercitivo pode levar a situações de conflito geradas por problemas de ação coletiva. À medida que diferentes atores contracenam na busca pela satisfação dos seus interesses individuais, o bem coletivo, que neste caso é a manutenção da floresta, fica comprometido, podendo levar à "tragédia dos bens comuns" (Hardin, 1968). 
Evidentemente, a visão da floresta como um bem comum está longe de ser consensual para todos os atores presentes na Amazônia, em particular na área de influência da BR-163. Não obstante, de acordo com as normas brasileiras, o ambiente, assim como os bens ambientais que o integram (também chamados de recursos ambientais - água, floresta, flora, fauna, biodiversidade etc.), são bens de uso comum do povo e, por isso mesmo, têm sua apropriação e o seu uso privado controlados (Benatti, 2005, p. 208209). Em outras palavras, esses recursos não podem ser apropriados e utilizados com o fim específico de atender o interesse privado. A apropriação privada dos recursos naturais deve respeitar e assegurar a manutenção do equilíbrio ambiental, de forma que a sua utilização não comprometa o bem-estar da coletividade.

Entretanto, o que se observa na área de influência da BR-163 é que as atividades voltadas para o interesse privado, desenvolvidas essencialmente - mas não só - pelas elites dominantes (empresários do agronegócio, pecuaristas e madeireiros), são uma constante. Embora o discurso desses segmentos já incorpore conceitos de desenvolvimento, sustentabilidade e qualidade de vida, as suas práticas atestam que a manutenção do bem comum está bastante comprometida. É a lógica do free-rider discursivo, segundo a qual "o que se diz não é feito e o que se faz não é dito" (Fonseca; Bursztyn, 2007, p. 181).

Em outras palavras, a falta de uma punição para os infratores do bem comum e/ou de incentivo para que esses atores se engajem na produção do bem comum faz com que se instaure o dilema da ação coletiva, ou, ao contrário, o problema do free-rider (carona). Isso ocorre quando alguém aposta na possibilidade de se beneficiar da ação coletiva dos demais membros do grupo - no caso, daqueles que, de fato, trabalham para a manutenção da qualidade de vida por meio da conservação da floresta - sem incorrer nos custos da participação. Pode-se dizer, portanto, que o dilema da ação coletiva 
aparece quando o interesse privado se sobrepõe aos esforços para a obtenção do bem comum.

No caso específico da área de influência da BR-163, são muitos os interesses e atores e são numerosas as possibilidades de alianças e rivalidades entre eles. Para este artigo, no entanto, consideramos apenas dois grupos. No primeiro foram incluídos atores que agem sob uma ótica puramente econômica e imediata, representados pela indústria madeireira e pelo segmento do agronegócio - aqui tratados como "dominantes". No outro, os que visam à manutenção de seu modus vivendi essencialmente dependente da floresta, que são os pequenos agricultores, os ribeirinhos e as comunidades tradicionais - os "dominados". Evidentemente, essa divisão simplifica bastante a realidade local, mas é suficiente para desenvolver a análise pretendida.

O desequilíbrio entre os dois grupos considerados, aliado ao baixo poder de ação da comunidade cívica ${ }^{4}$ amazônica, cria um vácuo de poder regional, dando margens a que o cenário político mantenha determinadas práticas clientelistas e absorva propostas advindas de grupos externos à região, nem sempre conhecedores da realidade local. É nesse contexto que a alocação de capital social pode desempenhar um papel relevante. De acordo com Bourdieu (2003), em um campo no qual coexistam atores dominantes e dominados, sempre haverá disputa por legitimidade, reconhecimento e poder. Nesse campo, a alocação de capital social varia de acordo com o contexto em que se processa, podendo estar entre dominantes e dominados, e, uma vez que esse capital está intimamente ligado ao prestígio, ao status e à mobilização de redes sociais, o seu reconhecimento em determinada comunidade pode representar a transferência de legitimidade para os representantes locais, enfraquecendo - ou mesmo anulando - o poder das elites locais dominantes.

Dessa forma, a intervenção da sociedade, por meio da criação de uma instituição social, pode representar uma alternativa para 
minimizar conflitos. Essa instituição, entendida como qualquer forma de coordenação de uma ação de indivíduos que interagem social e economicamente, pode ser representada pela sociedade, pelo Estado ou pelo mercado.

\section{Sociedade, Estado e mercado na região da BR-163}

Conforme visto até aqui, as diferentes formas de ocupação do território amazônico e de uso dos seus recursos naturais são a síntese de diferentes contextos históricos, sociais, políticos e econômicos pelos quais passou e ainda passa o Brasil. Neste espaço, ainda em formação e consolidação, tiveram grande importância as intervenções governamentais em diferentes níveis, os movimentos sociais, os grupos de interesse (mineradores, indústrias madeireiras, pecuaristas etc.), as organizações não-governamentais nacionais e internacionais, entre outros. Mais recentemente, novos atores passaram a integrar esse cenário, notadamente os grandes produtores e empresários do agronegócio.

Dada essa diversidade de fatos e atores, é difícil haver um entendimento único sobre o melhor uso dos recursos naturais da região. Por se tratar de uma região de fronteira, a Amazônia vem sendo marcada pela incorporação de terras e de recursos naturais, realizada, via de regra, dentro de uma lógica puramente econômica, e, mais do que isso, insustentável. Resulta daí o cenário de devastação ambiental em que se encontram muitos trechos da região, cenário este percebido principalmente pelo incremento das já elevadas taxas de desflorestamento observadas nas últimas décadas.

Parte dessa situação é atribuída à inoperância do poder público e dos organismos governamentais. Embora haja alguns avanços no estabelecimento de instrumentos e mecanismos de regulação (sistemas de monitoramento, cadastro e licenciamento ambiental de propriedades rurais, por exemplo), o Estado ainda não conseguiu 
internalizar a questão ambiental nos diversos níveis do processo decisório político. Há eixos de ação governamental em que ocorrem ações contraditórias com as próprias regulamentações estabelecidas pelo poder público (Bursztyn et al., 2004, p. 288). Embora o processo de planejamento governamental, nos diversos níveis, tenha adotado o discurso da sustentabilidade, na prática, ainda prevalecem a racionalidade econômica e imediatista e os interesses de pequenos grupos, gerando conflitos de diferentes ordens.

A reduzida eficiência do Estado em termos de ordenamento e controle do uso dos recursos naturais é, pois, resultado de uma estrutura operacional inadequada e da grande dimensão territorial da Amazônia (Pádua, 2000, Becker, 2005). Para mudar esse quadro, deve-se entender os diferentes projetos geopolíticos e os seus respectivos atores - que estão na base dos conflitos -, de forma a encontrar a melhor maneira de compatibilizar o crescimento econômico com a conservação dos recursos naturais (Becker, 2005, p. 72).

Assim, para que as políticas públicas, notadamente as ambientais, prevaleçam sobre a lógica do mercado, é preciso que haja maior interação - e responsabilização - entre os setores do governo e os não-governamentais. O planejamento integrado na elaboração das políticas de desenvolvimento pode reduzir impactos ambientais e evitar ações contraditórias. Da mesma forma, o envolvimento da sociedade civil, por meio de uma participação mais direta e ativa no processo de formulação e implementação das políticas públicas, pode trazer contribuições expressivas ao processo, notadamente no que tange às especificidades locais.

É o que vem se tentando no caso do asfaltamento da rodovia BR-163. Esta rodovia fez parte de um programa de desenvolvimento iniciado na década de 1970, quando outras grandes rodovias foram planejadas/construídas na região amazônica (notadamente a Transamazônica), com o objetivo de integrar a região ao resto do 
país. Ainda que a sua abertura tenha sido realizada naquele período, grande parte de seus $1.756 \mathrm{~km}$ de extensão encontra-se abandonada (principalmente os $956 \mathrm{~km}$ localizados no estado do Pará), haja vista a sua não-pavimentação (Leite, 2005). No Mato Grosso, boa parte da rodovia foi pavimentada, mas alguns trechos estão em péssimo estado de conservação e trafegabilidade. A pavimentação incompleta dessa rodovia, aliada às péssimas condições de tráfego nos trechos asfaltados, faz com que a ligação assinalada nos mapas oficiais seja efêmera e não atenda aos propósitos iniciais (Alencar et al., 2005).

A BR-163 adquire especial importância no cenário atual, uma vez que desponta como solução para o escoamento dos grandes volumes de soja produzidos no norte do Mato Grosso para o porto de Santarém, no Pará, de onde partem navios rumo aos mercados consumidores do hemisfério norte. Ao encurtar distâncias, a rodovia se torna elemento de grande potencial, uma espinha-dorsal da fronteira do desmatamento (Brasil. MMA/Pnuma, 2006). A pavimentação do trecho paraense e a recuperação do restante da rodovia representam, pois, uma considerável redução nos custos de transporte da produção agropecuária regional. Além disso, possibilita o escoamento de outros produtos e facilita o acesso a serviços de saúde e educação por parte das populações que padecem com a atual falta de trafegabilidade da rodovia. A ligação efetiva dos centros de produção de soja na região central do Mato Grosso com os portos do rio Amazonas pode gerar uma economia de mais de US\$ 11,6 por tonelada de soja para os produtores localizados ao longo dessa rodovia (Geipot, 2001, apud Alencar et al., 2005), além de viabilizar a expansão desta cultura e de cultivos associados (particularmente o arroz) para as áreas aptas à mecanização na sua área de influência.

Entretanto, caso esse processo não seja acompanhado de investimentos em planejamento e ordenamento territorial, pode representar a reprodução de situações de degradação ambiental e social observadas em outras rodovias da região (Fearnside, 2005b). 
A especulação fundiária e a corrida pelos recursos naturais têm acirrado conflitos fundiários e aumentado os casos de violência e assassinatos no campo, além de acelerar o processo de desmatamento (Bartholo et al., 2005, p. 43). Entre 1998 e 2004, o preço da terra no trecho paraense da rodovia saltou de uma média de $\mathrm{R} \$ 70,00$ para $\mathrm{R}$ \$ 3.000,00 o hectare; nas regiões mais dinâmicas do Mato Grosso, o hectare chegou a ser vendido por R\$ 10.000,00 (Brasil. MMA/ Pnuma, 2006, p. 43). Com relação ao desmatamento, estima-se que, dos 2,2 milhões de hectares de floresta suprimidos na Amazônia apenas no ano de 2004, 55\% ocorreram na área de influência da BR163 (Carneiro Filho, 2005, p. 191).

Sabendo da relação histórica que existe entre estradas e desmatamentos na Amazônia, ${ }^{5}$ e preocupado com um possível processo de exclusão social na região, o Ministério do Meio Ambiente (MMA) elaborou o Plano de Desenvolvimento Sustentável para a área de influência da BR-163 (PBR163). ${ }^{6} \mathrm{O}$ seu propósito, como diz o próprio nome, é promover um modelo de desenvolvimento sustentável para a região, em que o mercado não seja o único determinante (Brasil, 2006). De maneira bastante resumida, o PBR163 pretende planejar e implementar um conjunto de políticas estruturantes, de forma a conciliar o crescimento econômico e a integração nacional com a justiça social e a conservação e o uso sustentável dos recursos naturais.

Para Bertha Becker, o Plano Amazônia Sustentável (PAS), no qual se insere o PBR163, constitui um marco nas políticas públicas para a Amazônia e um grande desafio para alcançar o desenvolvimento regional com sustentabilidade. Trata-se de um planejamento associado a um projeto nacional que não visa apenas ao desenvolvimento. Ao contrário dos programas de governo anteriores (Brasil em Ação e Avança Brasil), também visa ao estabelecimento de compromisso social e ambiental e à valorização do território, em termos de regionalização de políticas e programas, mediante o 
fortalecimento de arranjos produtivos locais (Becker, 2004, p. 140141).

Em outras palavras, esse plano reconhece a diversidade como elemento orientador de ações específicas e diferenciadas que devem ser implementadas com base no diálogo com as sociedades regionais e sub-regionais. Isso deve ocorrer para que o processo democrático se fortaleça e, de fato, se construa uma identidade regional e se faça a identificação de parceiros para as ações de desenvolvimento. Com efeito, o PBR163 é o resultado de um longo processo de articulação entre os movimentos sociais e as instituições ambientais que atuam na Amazônia. No nível local, as discussões sobre a expansão da fronteira agrícola na área de influência da BR-163 tiveram início ainda em 2001, quando a organização não-governamental Instituto de Pesquisa Ambiental da Amazônia (Ipam) desenvolveu vários trabalhos de mapeamento participativo, com vistas a identificar as áreas de conflitos, os usos e as formas de ocupação e a levantar demandas, problemas e tendências junto aos principais líderes do movimento social e aos governos municipais (Leite, 2005).

Em 2003 foram realizados encontros regionais nas cidades de Altamira, Itaituba e Santarém, no Pará, e em Sinop, no Mato Grosso, com o objetivo de debater os problemas sociais, econômicos, ambientais e culturais que o asfaltamento poderia gerar e/ou agravar. As propostas surgidas durante cada encontro regional foram sistematizadas e consensuadas durante o encontro "O Desenvolvimento que queremos - ordenamento territorial da BR-163, Baixo Amazonas, Transamazônica e Xingu”, ocorrido em Santarém, em 2004. Ali foram estabelecidas as diretrizes do "Plano de Desenvolvimento Territorial Integrado e Sustentável da Região de Influência da BR-163", consolidadas no documento conhecido como "Carta de Santarém", 7 que foi apresentado aos representantes dos governos estaduais e federal e a outros parceiros da sociedade civil organizada e da comunidade científica, em abril de 2004, em 
Brasília. Ainda como resultado desse processo, foi formado o Fórum dos Movimentos Sociais da BR-163, que mais tarde se transformaria no Consórcio de Desenvolvimento Socioambiental da BR-163 (Condessa). ${ }^{8}$

Paralelamente à mobilização social, o governo federal instituiu, em 15 de março de 2004, por decreto, o Grupo de Trabalho Interministerial (GTI), responsável pela elaboração e implementação do PBR163. Inicialmente, eram 14 ministérios, sob a coordenação da Casa Civil da Presidência da República. Enquanto o plano era elaborado, foram incorporadas outras instituições, totalizando, ao final dezessete Ministérios, além das Secretarias Geral e de Relações Institucionais da Presidência da República.

No mesmo período foi desencadeado outro processo de planejamento, voltado especificamente para o controle do desmatamento na Amazônia: o "Plano de Ação para Prevenção e Controle do Desmatamento na Amazônia Legal" (PPCDAM). Da mesma forma que para o PBR163, foi instituído um GTI, denominado "Grupo Permanente de Trabalho Interministerial para a Redução dos Índices de Desmatamento na Amazônia Legal” (GPTI). Vinculado ao PPA 2004-2007 e sob a coordenação da Casa Civil, o PPCDAM contou com a colaboração de 13 ministérios, além de órgãos a eles vinculados, como Funai, Incra, Ibama e Polícia Federal. O resultado foi um conjunto de 162 atividades, agrupadas em 32 ações estratégicas, que integravam, por sua vez, três eixos temáticos: ordenamento territorial e fundiário, monitoramento e controle e fomento a atividades sustentáveis. Em sua essência, esses eixos coincidem com três dos cinco eixos definidos no PBR163, o que indica uma certa coerência entre as duas políticas.

Entretanto, no início de 2008, na seqüência de três anos de redução nas taxas de desmatamento na Amazônia, os resultados apresentados pelo Sistema de Detecção do Desmatamento em Tempo 
Real (Deter), do Inpe, demonstravam uma inflexão ascendente no nível do desmatamento na região. Nesse ano, o Pará foi o líder do desmatamento, com 42,6\%, seguido pelo Mato Grosso, com 41,8\%. Cabe indagar, então: se ambos os planos foram construídos de maneira integrada e com base na "ampla participação social", por que não atingiram os seus objetivos, notadamente no que tange ao controle do desmatamento?

\section{Desflorestamento na área de influência da BR-163: uma questão de governança}

Cada vez mais as políticas públicas surgem como construções sociais resultantes de processos de ação coletiva que associam diferentes categorias de atores públicos e privados (Callon; Lascoumes; Barthe, 2001). Esse parece ser o caso da construção do PBR163, gerado a partir de uma situação de conflito e ilegalidade no acesso aos recursos naturais, situação essa que gerou cobranças em relação à atuação das instituições governamentais na região, principalmente no que toca à ocupação de terras. Essas demandas, levantadas durante os vários encontros e consultas públicas, se concentraram em torno do tema da governança, que se refere ao exercício da autoridade, ao controle, à gestão e ao poder de governo. É também o modo como a autoridade é exercida no gerenciamento dos recursos do país, em direção ao desenvolvimento e ao modus operandi das políticas públicas governamentais ${ }^{9}$ (World Bank, 1992, Santos, 1997).

Entretanto, uma avaliação do planejamento realizado pelo governo federal na área de influência da BR-163 revela que questões típicas da "boa governança", tais que a forma de implementação das ações, a disponibilidade de recursos e o modelo de gestão do plano, ainda permaneciam - e permanecem - sem respostas (Brasil. MMA/Pnuma, 2006). Embora o PBR163 tenha incorporado todos os elementos essenciais para o desenvolvimento da região, não conseguiu traduzir as suas "intenções" em ações concretas. 
Pela falta de atuação no nível local/regional, ${ }^{10}$ os órgãos federais passam a ser meros planejadores do desenvolvimento da região. Na prática, a configuração da ocupação territorial obedece a iniciativas e decisões de grupos oligárquicos, donos do poder local (Bartholo; Delamaro; Tunes, 2005, p. 5), para os quais a racionalidade econômica prevalece sobre a preocupação com o caráter sustentável do desenvolvimento.

Nesse contexto, merece destaque o fato de que as raras reivindicações dos grupos empresariais dominantes ${ }^{11}$ quase não foram consideradas, o que implica dizer que esses grupos, mais fortes e organizados, não tinham interesse direto no plano como um todo, mas somente no asfaltamento da rodovia (Toni; Machado, Pinto, 2006). Indica também que esses atores, por terem canais de influência diretos junto ao governo federal, preferiram utilizá-los a participar dos longos processos de consultas públicas.

Assim, pode-se dizer que o processo de construção do PBR163 contribuiu para o fortalecimento de setores sociais politicamente mais fracos e dominados, mas não foi capaz de alterar a racionalidade individual e os interesses privados, essencialmente econômicos, que continuam a predominar sobre o bem comum e os interesses coletivos. A mobilização de redes sociais, neste caso, não foi suficiente para reverter a força e o prestígio das elites dominantes e, tampouco, para modificar a realidade local.

O resultado foi que, depois de mais de cinco anos de discussões, as medidas previstas no PBR163 ainda não foram implementadas ou têm sido pouco efetivas em termos de redução, ou mesmo controle, das taxas de desflorestamento. Com efeito, levantamentos realizados pelo Ipam indicam que, apesar de todos os avanços de organização dos movimentos sociais e de governança, já ocorreu mais da metade do desmatamento previsto no cenário otimista desenhado para a região, ${ }^{12}$ alcançando, em 2004, o nível previsto para o ano 
de 2006. Esses dados são corroborados pelas estimativas do Projeto de Monitoramento da Floresta Amazônica por satélite, do Instituto Nacional de Pesquisas Espaciais (Prodes/INPE), segundo as quais os Estados de Mato Grosso e Pará - cortados pela BR-163 - foram responsáveis por cerca de $70 \%$ do desflorestamento observado em 2006-2007 (Prodes/Inpe, 2007).

Novas medidas estão sendo propostas, como o recadastramento de propriedades rurais localizadas nos municípios mais desmatados (Decreto $n^{\circ}$ 6.321/2007) e uma resolução que condiciona a cessão de crédito rural ao cumprimento da legislação ambiental (Resolução $\left.n^{0} 3.545 / 2008\right)$. Entretanto, as decisões tomadas nos processos de formulação das políticas públicas - com ou sem a participação da sociedade civil - só serão de fato implementadas e bem-sucedidas se houver instituições capazes de levar adiante essas decisões e uma sociedade cidadã apta a acompanhar e controlar a realização das atividades previstas e a superar o dilema da ação coletiva, exercendo, assim, controle social sobre as ações do governo (Ostrom, 1990). Sem isso, a Amazônia Legal continuará sendo um "lugar sem Estado", uma área em que os governos (federal e estaduais) não governam e onde a ausência do Estado é preenchida por formas privadas e nem sempre lícitas de regulação, ou seja, um lugar onde impera a lei do mais forte (Bursztyn, 2007). O controle do desflorestamento na Amazônia depende da capacidade de o Estado exercer o poder que lhe é delegado, democraticamente, para governar em benefício de todos.

Cada vez mais se reconhece que Estados e sistemas políticos precisam ter capacidade para absorver e refletir sobre as novas práticas dos movimentos sociais, combinando as políticas públicas com o capital social que a própria sociedade constrói por meio de suas organizações. Fica evidente também que o modo de intervenção pública típico da lógica keynesiana (Estado interventor) já não 
corresponde às condições atuais. Novas fórmulas, mais criativas e descentralizadas, devem ganhar espaço.

O estabelecimento de incentivos e instrumentos econômicos que valorizem a manutenção da floresta, ou a sua recuperação (onde ela foi suprimida), também deve ser priorizado. Além de o crédito ser condicionado ao respeito ao meio ambiente como forma de induzir mudanças de comportamento em prol da sustentabilidade, há que se ter mecanismos para pagamento por serviços ambientais, linhas de financiamento específicas para a recuperação de áreas degradadas e sistemas de certificação legitimados pelo governo federal.

\section{Considerações finais}

Não é fácil organizar iniciativas de promoção da participação ou de articulação de atores sociais que tenham simultaneamente escopo territorial e setorial mais amplo, menos ainda em áreas tensas e conflituosas, como é o caso da área de influência da BR-163. Igualmente raras são as organizações e instituições que congregam e articulam atores sociais com diferentes interesses (econômicos, sociais, ambientais, políticos etc.) e em escala regional. Somadas, essas carências contribuem para que não haja uma comunidade cívica definida. Isso dificulta a compreensão acerca do grau de interdependência entre os interesses de atores sociais e políticos que convivem nesses espaços. Para alterar essa dinâmica, é preciso rever o papel do Estado e de suas instituições, bem como identificar as contribuições que a sociedade pode prestar no processo de desenvolvimento e consolidação regional.

Processos participativos que abrangem grandes áreas têm sido uma constante na elaboração de novas políticas. Prova disso é a realização de inúmeras audiências e consultas públicas, além das incontáveis conferências estaduais, regionais e nacionais, todas desenhadas para discutir questões que, de alguma maneira, 
tornar-se-ão objeto de um plano ou política. Entretanto, é comum que esses eventos se limitem à identificação de demandas de determinados grupos que conseguem se fazer representar nesses espaços de diálogo, em detrimento de outros grupos, mal representados ou mesmo não-representados. Superar essa limitação implica mais do que considerar os custos de realização das consultas e conferências. Requer o acompanhamento e monitoramento do processo participativo, de forma a garantir que todos os atores, direta ou indiretamente envolvidos, estabeleçam pactos em prol do bem comum. Envolve ainda o reconhecimento da necessidade de instituições fortes, capazes de reduzir as incertezas que permeiam as interações entre os diferentes atores, de forma a fazer valer as regras acordadas em cada processo.

Muitas vezes, a sociedade cria as suas próprias instituições (formais ou informais) que levam ao acúmulo de capital social. Daí a necessidade de se levar em conta os "arranjos locais" nos processos de elaboração de políticas públicas, haja vista que a democratização das relações sociais pode levar à redução do poder das elites dominantes e à conseqüente quebra de práticas clientelistas e insustentáveis. Nesse sentido, acredita-se que a solução para os problemas dos recursos comuns deve levar em conta também as perspectivas dos indivíduos que farão as suas escolhas, inclusive daqueles que detém o poder local. A compreensão dessas condições estruturais traz uma importante contribuição para a análise do comportamento dos atores em relação do desflorestamento na região amazônica. Entretanto, essas explicações têm caminhado à margem de uma análise mais refinada sobre como esses mesmos atores se inter-relacionam e tomam as suas decisões (Muchagata, 2004).

O Estado deve se valer de seu poder de imposição e de regulação, mas também de mecanismos econômicos capazes de interferir em comportamentos individuais. Em outras palavras, além do estabelecimento conjunto das regras do jogo, é preciso reforçar o 
papel do Estado como agente regulador e mediador de conflitos, de forma a garantir o cumprimento dos acordos e pactos, e da sociedade como controladora da aplicação das regras (controle social). O Estado passaria a ser o árbitro na relação entre as partes, o "terceiro elemento", necessário para quebrar a lógica da abertura de novas áreas a serem ocupadas e de aumento do desflorestamento.

\title{
Deforestation in the Brazilian Amazon: colective action, governance and governability in boundary areas
}

\begin{abstract}
The text analyzes settlement policies and land use processes in the Brazilian Amazon rain forest region and their relation with the evolution of regional deforestation rates. For that purpose, the concepts of social capital, collective action and governance were used to explain practices and activities carried out by selected actors present in the area of influence of the BR-163 highway (CuiabáSantarém). Results indicate that the success of these policies depends on the State's effective presence in the region, by means of the deployment of regulatory instruments. Also, these actions have to consider local power relationships and how they reflect themselves in Amazon deforestation rates. Finally, it is shown that the establishment of economic mechanisms and incentives could contribute to changing actors' individual behavior.
\end{abstract}

Key words: Amazon deforestation; social participation; economic mechanisms; public policies.

\section{Notas}

1 De acordo com Angelsen e Kaimowitz (1999), uma abordagem lógica para a análise do desflorestamento deve ser feita em três níveis: fontes, causas imediatas e causas subjacentes. As fontes são as ações dos agentes, como pequenos agricultores, pecuaristas, madeireiros, grandes fazendeiros etc., e podem ser medidas diretamente. As causas imediatas focalizam os parâmetros de decisão disponíveis, tais como preços, custos de oportunidade, restrições governamentais, tecnologia etc. As causas subjacentes influenciam as decisões dos agentes por meio de diferentes canais, quais sejam disseminação de novas tecnologias e informação, desenvolvimento de infra-estrutura, políticas de governo e variáveis macroeconômicas. 
2 Um "estado de coisas" é uma situação que se arrasta durante um tempo razoavelmente longo, incomodando grupos de pessoas e gerando insatisfações, sem, entretanto, chegar a mobilizar as autoridades governamentais (Rua, 1998). O desflorestamento, na verdade, já ultrapassou essa barreira. Entretanto, uma maneira eficaz de controle ainda não obteve um consenso.

3 A Amazônia Legal corresponde às áreas ao norte do paralelo $16^{\circ} \mathrm{S}$, do Estado do Mato Grosso, e ao norte do paralelo $13^{\circ} \mathrm{S}$, do Estado de Goiás, além da porção do Estado do Maranhão situada a oeste do meridiano $44^{\circ} \mathrm{W}$. Foi ampliada em 1977, quando incorporou todo o Estado de Mato Grosso, então criado. A Amazônia Legal corresponde hoje a aproximadamente cinco milhões de $\mathrm{km}^{2}$, ou $57,4 \%$ da área total do Brasil (Becker, 1998).

4 O conceito de comunidade cívica é apresentado por Putnam (2005) e se refere ao conjunto de cidadãos que participam nos negócios políticos, que demonstram interesse pelas questões públicas e que se devotam às causas públicas, buscando o bem público à custa do interesse puramente individual e particular.

5 Estudos atestam que elevada percentagem nos desmatamentos ocorridos na Amazônia nas últimas décadas ocorreu dentro de uma faixa que varia de 50 a $100 \mathrm{~km}$ de cada lado das rodovias pavimentadas (Alves, 1999, Nepstad et al., 2001, Margulis, 2002, Soares Filho et al., 2004, Fearnside, 2006b).

6 O PBR163 está inserido no Plano Amazônia Sustentável (PAS) que, por sua vez, é parte do Plano PluriAnual 2004-2007 do governo federal.

7 A Carta de Santarém apresenta um conjunto de demandas e propostas organizadas em cinco eixos temáticos: infra-estrutura e serviços básicos rurais e urbanos; ordenamento fundiário e combate à violência no campo; estratégias produtivas e manejo dos recursos naturais; fortalecimento social e cultural das populações locais; e gestão ambiental e monitoramento de áreas protegidas (o documento está disponível em http://www.ipam.org.br).

8 O Condessa conta com a participação de 32 organizações e visa representá-las junto ao governo, no tocante à discussão eà implementação da obra. 
9 Mais recentemente, o termo "governança ambiental" se popularizou nas referências a formas políticas, sociais e administrativas de regular o acesso e o uso dos recursos naturais. A governança ambiental pode ser exercida por instituições públicas e/ou por organizações da sociedade civil. Em ambos os casos, ocorre a maior ou menor incidência de regras de mercado (Vidal, 2005).

10 Pesquisa de campo realizada para o Projeto Avaliação e Planejamento Integrados - Setor Soja, na área de influência da BR-163, revela que os atores locais reivindicam fortemente uma presença mais atuante do Estado (entendido como governo federal) na região, principalmente na regulação da ocupação territorial. Conclui que "o PBR163 somente será mais que uma peça de retórica vazia se sua implementação for efetivamente acompanhada de um fortalecimento da governança em nível local/regional" (Bartholo et al., 2005: 4).

11 Toni e colaboradores (2006), ao analisarem a participação da sociedade civil no processo de construção do PBR163, apontaram que, à exceção de alguns registros isolados de demandas de madeireiros e pecuaristas, não foram apresentadas, durante as audiências e consultas públicas, as reivindicações dos grupos empresariais.

12 A partir de um modelo de mudanças de uso da terra, o Ipam produziu uma simulação do futuro da região afetada pela BR-163 para o ano 2026, com dois cenários possíveis: com e sem governança. No primeiro, presumiu-se uma presença governamental efetiva (aplicação da legislação ambiental e do Código Florestal); no segundo, assumiuse um desdobramento similar àquele ocorrido ao longo das últimas décadas, ou seja, ausência do Estado em regiões de fronteira. Em ambos os cenários haveria incremento das taxas de desflorestamento. Entretanto, no primeiro cenário, a presença do Estado poderia conter até $60 \%$ do desmatamento possível ao longo da rodovia, enquanto que, no segundo, sem governança, essa contenção chegaria a, no máximo, 34\% (Soares Filho et al., 2004). 


\section{Referências}

ABRAMOVAY, R. O capital social dos territórios: repensando o desenvolvimento rural. Economia Aplicada, n 2, v. 4, p. 379-397, abr./jun. 2000.

ALENCAR, A. et al. A pavimentação da BR-163 e os desafios à sustentabilidade: análise econômica, social e ambiental. Belo Horizonte: Conservation Strategy Fund (CSF/Brasil), 2005. Disponível em: <http://www.icv.org.br>. Acesso em: jun. 2006.

ALVES, D. An analysis of the geographical patterns of deforestation in Brazilian Amazonia - the 1991-1996 period. Trabalho apresentado na Conferência sobre Padrões e Processos de Uso da Terra e Mudança em Florestas na Amazônia, realizada na University of Florida, em Gainesville, Flórida, em março de 1999.

ANGELSEN, A.; KAIMOWITZ, D. Rethinking the causes of Deforestation: Lessons from Economic Models. The World Bank Research Observer, v.14, n. 1, p. 73-98, 1999.

AXELROD, R. 1981. The emergence of cooperation among egoists. American Political Science Review, v. 75, p. 306-318, 1981.

BARTHOLO, R.; DELAMARO, M.; TUNES, G. Muito além do asfalto: cenários amazônicos para a BR-163. Relatório de Pesquisa realizada no âmbito do Projeto Avaliação e Planejamento Integrados - setor de soja na área de influência da BR-163. Brasília: SDS, SCA/MMA, PNUMA, CDS/UnB, 2005.

BEBBINGTON, A. Social capital and development studies II: can Bourdieu travel to policy? Progress in Development Studies, v. 7, n. 2, p. 155162, 2007.

Social capital and development studies III: social capital and the state (seen from Peru). Progress in Development Studies, v. 8, n.3, p. 271-279, 2008.

BECKER, B. K. Amazônia. São Paulo: Ática, 1998. (Série Princípios, v. 192). 
BECKER, B. K. Amazônia: geopolítica na virada do III milênio. Rio de Janeiro: Garamond, 2004.

. Geopolítica na Amazônia. Estudos Avançados, v. 19, n. 53, p. 71-86, 2005.

BENATTI, J. H. O meio ambiente e os bens ambientais. In: RIOS, A. V. V.; IRIGARAY, C. T. H. (Orgs.). O direito e o desenvolvimento sustentável: curso de direito ambiental. São Paulo: Peirópolis; Brasília: IEB, 2005. p. 205-243.

BOURDIEU, P. The forms of capital. In: RICHARDSON, J. G. (Ed.). Handbook of theory and research for the Sociology of Education. New York: Greenwood Press, 1986. p. 241-258.

. O poder simbólico. 6. ed. Rio de Janeiro: Bertrand Brasil, 2003.

BRASIL. Grupo de Trabalho Interministerial do Plano de Desenvolvimento Sustentável para a Área de Influência da Rodovia BR-163. Plano de Desenvolvimento Sustentável para a Área de Influência da Rodovia BR-163. Brasília: Ministério do Meio Ambiente, 2006.

BRASIL. Ministério do Meio Ambiente (MMA). Programa das Nações Unidas para o Meio Ambiente (PNUMA). Avaliação e planejamento integrados no contexto do Plano BR-163 Sustentável: o setor soja na área de influência da rodovia BR-163 - relatório final. Brasília: MMA, PNUMA, 2006.

BURSZTYN, M. Políticas públicas para o desenvolvimento sustentável. In: BURSZTYN, M. (Org.). A difícil sustentabilidade: política energética e conflitos ambientais. Rio de Janeiro: Garamond, 2001, p. 59-76.

A exclusão e o local: tempos e espaços da diversidade social. In: DINIZ, C. C. (Org.). Políticas de desenvolvimento regional. Brasília: Universidade de Brasília, 2007. p. 79-102.

BURSZTYN, M. A.; BURSZTYN, M; ASSUNÇÃO, F. N. A. Aspectos legais e institucionais da gestão ambiental na Amazônia. In: SAYAGO, D.; TOURRAN, J. F.; BURSZTYN, M. (Orgs.). 
Amazônia: cenas e cenários. Brasília: Universidade de Brasília, 2004. p. 263-293.

CALLON, M.; LASCOUMES, P.; BARTHE, Y. Agir dans un monde incertain: essai sur la démocratie technique. Paris: Seuil, 2001.

CARNEIRO FILHO, A. Temos um esplêndido passado pela frente? As possíveis conseqüências do asfaltamento da BR-163. In: TORRES, M. (Org.). Amazônia revelada: os descaminhos ao longo da BR163. Brasília: CNPq, 2005. p.185-199.

CLEARY, D. After the frontier: problems with political economy in the modern Brazilian Amazônia. Journal of Latin American Studies, v. 25, p. 331-349, 1993.

CLEAVER, F. The inequality of social capital and the reproduction of chronic poverty. World Development, v. 33, p. 893-906, 2005.

COLEMAN, J. S. Foundations of Social Theory. Cambridge, Massachussets: Harvard University Press, 1990.

FEARNSIDE, P. M. Deforestation in Brazilian Amazonia: history, rates and consequences. Conservation Biology, v.19, n. 3, p. 680-688, 2005a.

FEARNSIDE, P. M. Carga pesada: o custo ambiental de asfaltar um corredor de soja na Amazônia. In: M. Torres (Org.). Amazônia revelada: os descaminhos ao longo da BR-163. Brasília: CNPq, 2005b. p. 387-423.

FEARNSIDE, P. M. Desmatamento na Amazônia: dinâmica, impactos e controle. Acta Amazonica, v. 36, p. 395-400, 2006 a.

FEARNSIDE, P. M. Containing destruction from Brazil's Amazon highways: now is the time to give weight to the environment in decision-making. Environmental Conservation, v. 33, n. 3, p. 181183, $2006 \mathrm{~b}$.

FERREIRA, A. M. M.; SALATI, E.; SANTOS, A. A. The large scale biosphere-atmosphere experiment in Amazonia: sub-componente 
dimensão humana. Fundação Brasileira para o Desenvolvimento Sustentável. [s. d.]. (não publicado).

FINE, B. The developmental State is dead: long live for social capital. Development and Change, v. 30, p. 1-19, 1999.

. Social capital versus social theory: political economy and social science at the turn of the millenium. London: Routledge Taylon \& Francis Group, 2001.

FONSECA, I. F.; BURSZTYN, M. Mercadores de moralidade: a retórica ambientalista e a prática do desenvolvimento sustentável. Ambiente \& Sociedade, v. 10, n. 2, p. 169-186, 2007.

HARDIN, G. The tragedy of the commons. Science, v.162, p. 1243-1248, 1968.

HARRISS, J. Public action and the dialectics of descentralisation: against the myth of social capital as "the missing link in development". Social Scientist, v. 29, n. 11-12, p. 25-40, 2001.

KITAMURA, P. C. A Amazônia e o desenvolvimento sustentável. Brasília: Embrapa-SPI, 1994.

LEITE, M. (Org.). Dez anos de IPAM: Instituto de Pesquisa Ambiental da Amazônia. São Paulo: Peirópolis, 2005.

MACHADO, L. O. R. Reforma agrária e desflorestamento na Amazônia: uma relação de causa e efeito? - o caso da região de Barreira Branca, Tocantins. 2002. Dissertação (Mestrado em Desenvolvimento Sustentável) - Universidade de Brasília, 2002.

MARGULIS, S. Quem são os agentes dos desmatamentos na Amazônia e por que eles desmatam? (concept paper para discussão). Brasília: Banco Mundial, 2002.

MIRANDA NETO, M. J. O enigma Amazônia: desafio ao futuro. Belém: Cejup, 1991.

MUCHAGATA, M. G. O papel das organizações de agricultores nas transformações recentes do uso do espaço em região de fronteira 
amazônica: o caso da região de Marabá. In: SAYAGO, D.; TOURRAND, J. F.; BURSZTYN, M. (Orgs.). Amazônia: cenas e cenários. Brasília: Universidade de Brasília, 2004. p. 237-260.

NEPSTAD, D. et al. Road paving, fire regime feedbacks and the future of Amazon forests. Forest Ecology and Management, v. 154, p. 395407, 2001.

OLSON, M. A lógica da ação coletiva: os benefícios públicos e uma teoria dos grupos sociais. São Paulo: Editora Universidade de São Paulo, 1999.

OSTROM, E. Governing the commons - the evolution of institutions for collective action. New York: Cambridge University Press, 1990.

PÁDUA, J. A. Biosfera, História e Conjuntura na Análise da Questão Amazônica. História, Ciência e Saúde, v. 6 (Suplemento). p. 793811, 2000.

PASQUIS, R.; MACHADO, L. O. R.; GUERRA, R. Diagnóstico dos formatos de ocupação do espaço amazônico. Brasília: MMA/SCA/ NAPIAm; Montpellier: Cirad, 2001.

PRODES/INPE. Monitoramento da floresta amazônica brasileira por satélite: 2005/2006, relatório anual. 2007. 24p. Disponível em: <http://www.obt.inpe.br/prodes>. Acesso em: set. 2008.

PUTNAM, R. D. Comunidade e democracia: a experiência da Itália moderna. 4. ed. Rio de Janeiro: Editora Fundação Getúlio Vargas, 2005.

RANKIN, K. N. Social capital, microfinance and politics of development. Feminist Economics, v. 8, n. 1, p. 1-24, 2001.

REYDON, B. P.; HERBERS, S. R. Política ambiental para a agropecuária na Amazônia e degradação do meio ambiente. $A B R A$, Campinas, SP, v. 19, n. 1, p. 42-52, 1989.

RODRIGUES, R. L. V. Análise dos fatores determinantes do desflorestamento na Amazônia Legal. 2004. Tese (Doutorado em 
Engenharia) - Universidade Federal do Rio de Janeiro.. Disponível em: <http://www.amzonia.org.br>. Acesso em: set. 2005.

RUA, M. G. Análise de políticas públicas: conceitos básicos. In: RUA, M. G.; CARVALHO, M. I. O estudo da política: tópicos selecionados. Brasília: Paralelo 15, 1998. p. 231-260.

SACHS, I. Caminhos para o desenvolvimento sustentável. Rio de Janeiro: Garamond, 2000.

SANTOS, M. H. C. Governabilidade, governança e democracia: criação de capacidade governativa e relações executivo-legislativo no Brasil pós-constituinte. Dados, v. 40, n.3, 1997. Disponível em: <http:// www.scielo.br>. Acesso em: jul. 2008.

SAYAGO, D.; MACHADO, L. O pulo do grilo: o Incra e a questão fundiária na Amazônia. In: SAYAGO, D.; TOURRAND, J. F.; BURSZTYN, M. (Orgs.). Amazônia: cenas e cenários. Brasília: Universidade de Brasília, 2004. p. 217-235.

SOARES FILHO, B. et al. Simulating the response of land-cover changes to road paving and governance along a major Amazon highway: the Santarém-Cuiabá corridor. Global Change Biology, v. 10, p. 745764, 2004.

TONI, F.; MACHADO, L. O. R.; PINTO, M. O. Políticas públicas e participação social: análise das demandas da sociedade civil na construção do Plano BR-163 Sustentável: relatório de pesquisa realizado no âmbito do Projeto Diálogos. Brasília: CDS/UnB, 2006.

VIDAL, M. P. Gobernanza ambiental descentralizada: oportunidades para la sostenibilidad y el acceso a los recursos naturales para los territorios rurales pobres. Santiago: Fondo Mink'á de Chorlaví, 2005. Disponível em: <http:///www.idrc.ca/uploads/userS/11304196171GAD-espanol.pdf>. Acesso em: jul. 2008.

WORLD BANK. Governance and development. Washington: World Bank, 1992. 